\title{
Calibration of the Latest Generation Superconducting Gravimeter iGrav-043 Using the Observatory Superconducting Gravimeter OSG-CT040 and the Comparisons of Their Characteristics at the Walferdange Underground Laboratory for Geodynamics, Luxembourg
}

\author{
Basem Elsaka, ${ }^{1,3}$ (D) Olivier Francis, ${ }^{2}$ and Jürgen Kusche $^{1}$
}

\begin{abstract}
In December 2019, the latest generation transportable superconducting gravimeter (SG) iGrav-043 purchased by the University of Bonn was installed in the Walferdange Underground Laboratory for Geodynamics (WULG) in the Grand Duchy of Luxembourg. In this paper, we estimate the calibration factor of the iGrav-043, which is essential for long-term gravity monitoring. We used simultaneously collected gravity data from the un-calibrated iGrav-043 and the calibrated Observatory superconducting gravimeter OSG-CT040 that operates continuously at WULG since 2002. The tidal analysis provides a simple way to transfer the calibration factor of one SG to the other. We then assess and compare tidal analyses, instrumental drifts and high frequency noises. After 20 years of continuous operation, the instrumental drift of the OSG-CT040 is almost zero. From 533 days of joint operation, we found that the instrumental drift of iGrav-043 exhibits a composite behavior: just after the setup and for two months a fast exponential decrease of $171 \mathrm{~nm} \mathrm{~s}^{-2}$, then a linear with a rate of $66 \mathrm{~nm} \mathrm{~s}^{-2} \pm 10 \mathrm{~nm} \mathrm{~s}^{-2}$ per year. We suggest that a period of 3 months is sufficient for calibrating the iGrav. Accidental electrical power cuts triggered slight differences in the reaction and recovery of the OSG-CT040 and iGrav-043. However, it has been found that the long-term linear behavior of the drift was not affected.
\end{abstract}

Keywords: Superconducting gravimeter, calibration factor, tides analyses, instrumental drift, gravity residuals.

\section{Introduction}

For more than 30 years, GWR Instruments at San Diego, California is the only company in the world

1 Astronomical, Physical and Mathematical Geodesy (APMG) Group, Institute of Geodesy and Geoinformation, University of Bonn, Bonn, Germany. E-mail: elsaka@geod.unibonn.de

${ }^{2}$ Faculty of Science, Technology and Medicine, University of Luxembourg, Esch-sur-Alzette, Luxembourg.

3 Geodynamics Department, National Research Institute of Astronomy and Geophysics (NRIAG), Helwan, Cairo, Egypt. manufacturing superconducting relative gravity meters (gravimeters). GWR now builds two versions: the iGrav transportable superconducting gravimeter (SG) and the Observatory SG (OSG) (see Fig. 1). Despite the higher cost of SGs with respect to spring relative gravimeters, they are nowadays considered as the most sensitive relative gravity instrument with lower noise and stable drift rate which can be modelled and corrected by comparing with absolute gravity measurements (see e.g. Warburton et al., 2010).

Both OSG and the iGrav instruments have been used in new applications such as monitoring of ground-water (e.g. Fores et al., 2017; Güntner et al., 2017), geothermal signals (e.g. Goto et al., 2020; Hinderer et al., 2015), measurement of silent earthquakes and assessing ocean-loading in order to improve global tidal models (see e.g. Okubo et al., 1997 and Boy et al., 2003). SGs have provided noninterrupted gravity observations with periods from one second to decades with an ultra-high precision that allows studying diverse geophysical phenomena. In hydrology applications, long-term monitoring using portable mechanical spring gravimeters such as CG-05 and CG-06 is highly influenced by the nonlinear drift effect. The drift problem has been eliminated by the long-term stability of SGs observations, since in these instruments the mechanical springs are replaced with the levitation of sphere as a test mass through magnetic suspension. Recently, Fores et al. (2019) demonstrated that a tilt-controlled gPhoneX (a relative spring gravimeter) provides comparable long-term stability.

In the summer of 2018, the Astronomical, Physical, Mathematical Geodesy (APMG) Group of the 
University of Bonn received the funding agreement from the German Research Foundation DFG (Deutsche Forschungsgemeinschaft) to aquire an iGrav SG. In December 2019, iGrav-043 has been delivered and we decided to move it to Walferdange Underground Laboratory for Geodynamics (WULG), Luxembourg, for calibration with the OSG-CT040 superconducting gravimeter. The WULG gravity station is located about $7 \mathrm{~km}$ north of the city of Luxembourg inside an abandoned gypsum mine $90 \mathrm{~m}$ under the surface (for a complete description see Francis \& van Dam, 2003). This site is characterized by excellent conditions for performing very high precision geophysical measurements, because of several advantages of the gypsum mine such as stable temperature, no running water, low anthropogenic noise level and easy access.

The OSG-CT040 installed in the Walferdange mine is recording continuously the variations of the gravity acceleration with a precision of $5 \mathrm{~nm} / \mathrm{s}^{2} / \mathrm{Hz}^{1 / 2}$ (Van Camp et al., 2005) since 2002. The long-term gravity changes are monitored with several annual absolute gravity measurements taken in between
European and International Absolute Gravimeters Comparisons (for example, Francis et al., 2013).

There are numerous studies investigating different approaches to estimate the calibration factor of the SGs. Some of them have used the measurements of the superconducting gravimeters themselves submitted to external masses or artificial accelerations (see e.g. Achilli et al., 1995; Richter et al., 1995; Falk et al., 2001). Nowadays, the favored technique is to calibrate SG measurements with absolute gravimeter ones (e.g. Hinderer, 1991; Francis, 1997; Francis et al., 1998; Almavict et al., 1998; Francis \& van Dam, 2002; Imanishi et al., 2002, Rosat et al., 2009; Merlet et al., 2021).

The originality of this paper lies in the transfer of the calibration factor between two SGs. Due to the SGs high precision, the procedure is extremely efficient. In addition, some authors investigated the behavior of the calibration factor after transporting the SG to another location (see e.g. Meurers, 2012; Schäfer et al., 2020). Meurers (2012) found that the calibration factor of the SG (C025 in his case) remained actually unchanged during the transfer of
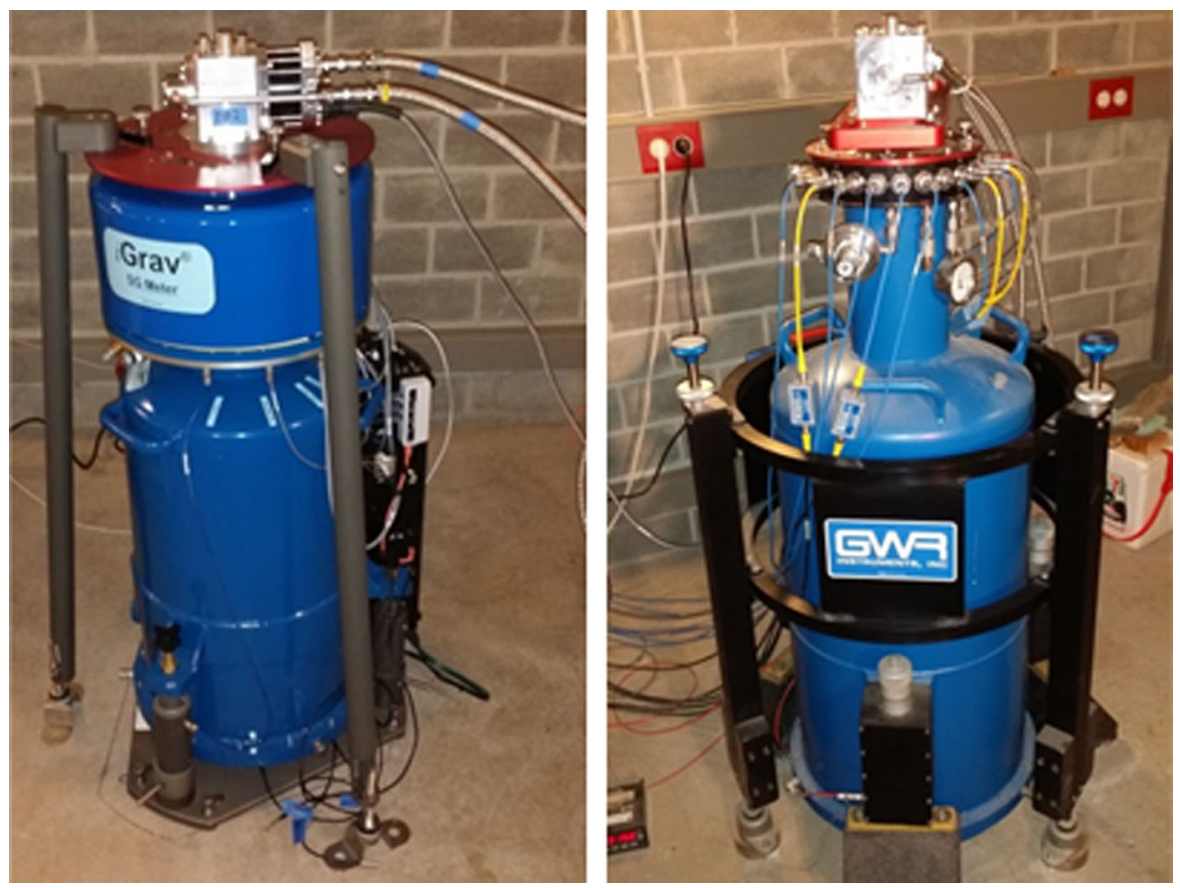

Figure 1

The iGrav-043 (left) and the OSG-CT040 (right) in the Walferdange Underground Laboratory for Geodynamics 
the SG (of about $60 \mathrm{~km}$ from Vienna to Conrad observatory). The same result was obtained by Schäfer et al. (2020), who have examined the stability of the calibration factors, noise levels and drift behavior after the transport of three iGrav SGs. They have found that the factors have been changed lesser than or equal to $0.01 \%$ and the drift behavior has not been affected by warm transport, whereas by cold transport, a change in the long-term quasi-linear drift may occur.

This paper is organized as follow: Sect. 2 overviews the operation concept of the iGrav-043 SG. The tidal analyses and calibration transfer in addition to investigating the drift behavior of both SGs will be described in Sect. 3. We also provide for the first time the instrumental drift behavior of the OSGCT040 and the iGrav-043 after an electrical shortage. Section 4 finally presents conclusions and outlook.

\section{The iGrav-043: Overview and Operation Concept}

The concept of the superconducting gravimeter goes back more than fifty years now (Prothero \& Goodkind, 1968). GWR (Goodkind, Warburton, and Reineman) Instruments Inc., established in 1979, manufactured the first SGs for the Royal Observatory of Brussels, Belgium (ROB) and for the Institut für Angewandte Geodäsie, Germany (IfAG), the predecessor agency of the Bundesamt für Kartographie und Geodäsie (BKG). As nicely summarized in Hinderer et al., (2007), numerous modifications and improvements have been developed and implemented at GWR Instruments to arrive at the current SG performance (see e.g. Richter \& Warburton, 1989; Warburton \& Brinton, 1995; Warburton et al., 2000). However, for nearly forty years the basic sensor configuration of the SGs has remained unchanged; improvements generally focus on rendering the instruments more user-friendly as a research tool.

In the early 80ies, the TT30 superconducting gravimeter was installed at ROB and continued to measure without major interruptions until it was decommissioned in year 2000 (Hinderer et al., 2007; Melchior et al, 1996). As Helium was very expensive, IfAG asked GWR Instruments to develop a cryogenic refrigerated dewar system. This led to the design with coldhead and compressor (see Fig. 2) which is still followed in current instruments, where the flow of heat is reduced via radiation and conduction from the outside of the dewar to its belly. The TT40 went to the basement of a castle at Bad Homburg, Germany, and it was extremely successful with a hold time of well over 400 days versus 50 days unrefrigerated (Hinderer et al., 2007). Four years later the TT40 was joined by TT60, and parallel recordings allowed a better understanding of the instrument (Richter, 1990).

GWR manufactured twelve instruments (TT70) between 1986 and 1994. The TT70 had internal tiltmeters and thermal levelers to keep the SG automatically aligned with the direction of gravity. The coldhead could be more easily removed for servicing and maintenance (Warburton \& Brinton, 1995). Subsequently, GWR developed a smaller and more compact dewar design with a height of about one meter and a weight of $90 \mathrm{~kg}$. For more details and literature, the reader is referred to Hinderer et al. (2007).

Inherited from earlier SG types, the iGrav SG consists of three main parts: the dewar, the compressor and the computer unit. The main dewar (Fig. 2c) contains the test mass, head electronics and cold head. The compressor (Fig. 2b) is responsible for supplying the main dewar with Helium gas to regulate the dewar temperature. The computer unit (Fig. 2d) holds the operating system, data acquisition control box and software. In order to ensure continuous measurements, GWR provides an uninterrupted power supply (UPS), which in the event of a power failure will provide power to the control box for up to $24 \mathrm{~h}$.

The operation concept of the iGrav SG relative gravimeter is based on a hollow superconducting niobium sphere as a proof 'test' mass (Fig. 2a) which is levitated through magnetic suspension force. The magnetic force is generated by superconducting coils, which are placed in superconducting shield. The Niobium superconducting shield surrounds the magnetic body and prevents external changes of the magnetic field from affecting the levitation field. Two coils guarantee that small variations in the gravity field induce a large variation in the sphere position, which can be detected by an electrostatic device. 


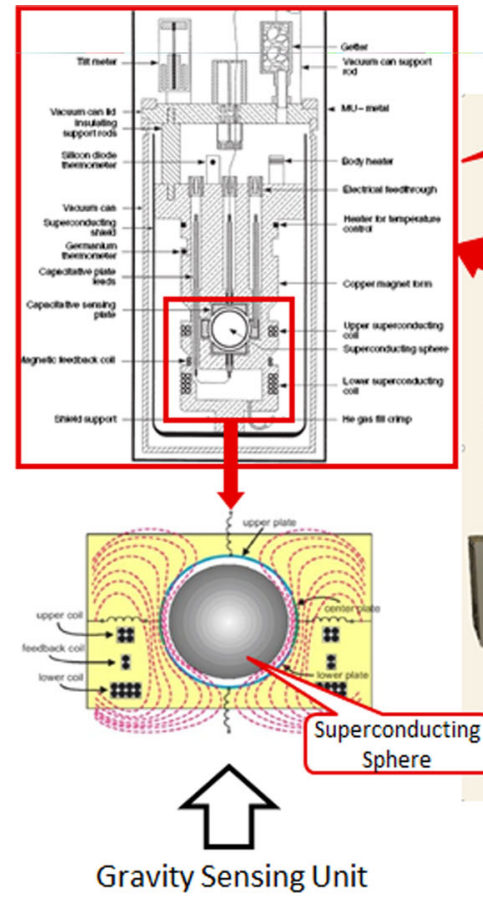

(a)

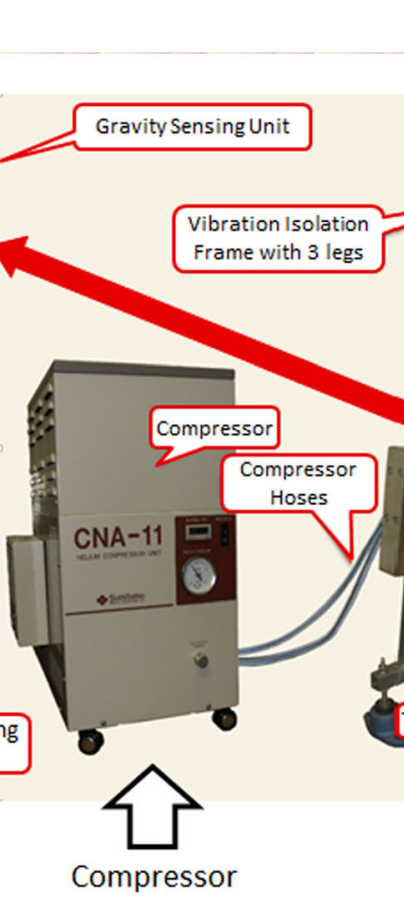

(b)

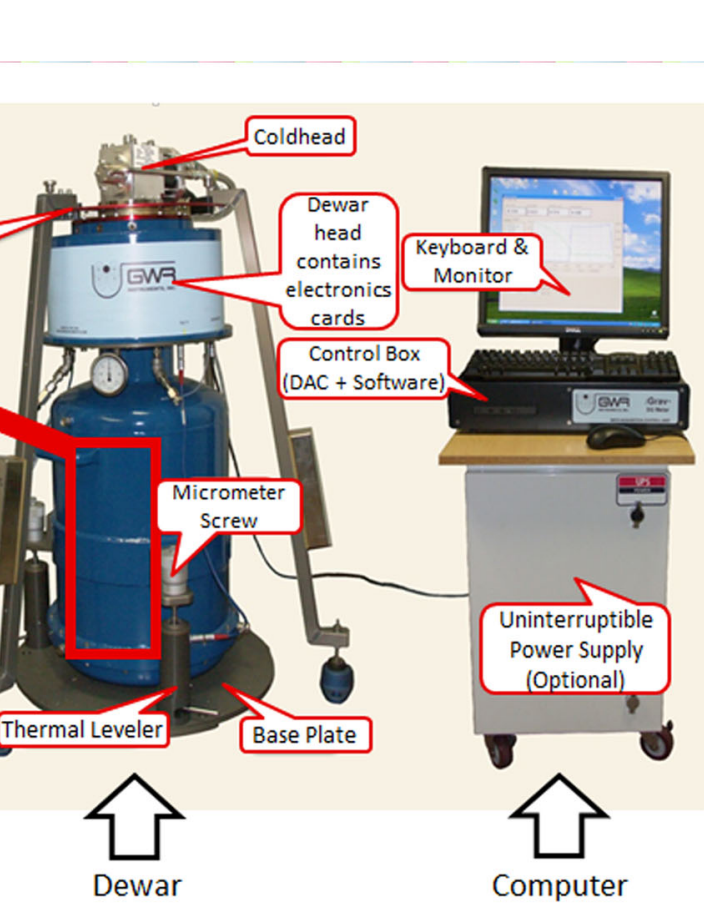

(c)

Figure 2

The iGrav components including a Gravity Sensing Unit, b Compressor, c Dewar, control electronics and Cold head, and d Computer Unit (after iGrav User Guide 2019)

Then, a feedback magnetic coil will generate an additional magnetic force that brings the sphere back to its initial position. As a result, the feedback integrator voltage is linearly proportional to gravity changes.

To maintain the state of superconductivity, the iGrav dewar (Fig. 2c) holding the gravity sensor 'sphere' (Fig. 2a) must be filled with liquid Helium to keep the temperature close to $4.2 \mathrm{~K}\left(=-268,95{ }^{\circ} \mathrm{C}\right)$. The compressor (Fig. 2b) is used to keep the cold head cool enough to liquefy the Helium gas. The dewar head contains control electronics (Fig. 2c), which constantly acquire and control different data (such as gravity, temperature, and tilt signals). In addition, they maintain dewar pressure, and retrieve data from external devices (such as the barometer and GPS clock).

\section{Data Calibration and Analysis}

We consider data collected during 533 days of simultaneous operation of the OSG-CT040 and iGrav-043. In the WULG laboratory, the two instruments operated in two different rooms $15 \mathrm{~m}$ apart. The calibrated measurements are displayed in Fig. 3. In this section, we explain how the calibration factor of the iGrav-043 was determined by transferring the calibration from the OSG-CT040. We also assess the high frequency instrumental noise in both data records and we compare the drift behavior.

\subsection{Tidal Analyses and Calibration Transfer}

Superconducting gravimeters are delivered without a calibration factor. It is the responsibility of the operator to determine the scale factor (hereafter called the Calibration Factor or $\mathrm{CF}$ ) between the output voltage and the gravity change in $\mathrm{nm} \mathrm{s}^{-2}$. The 


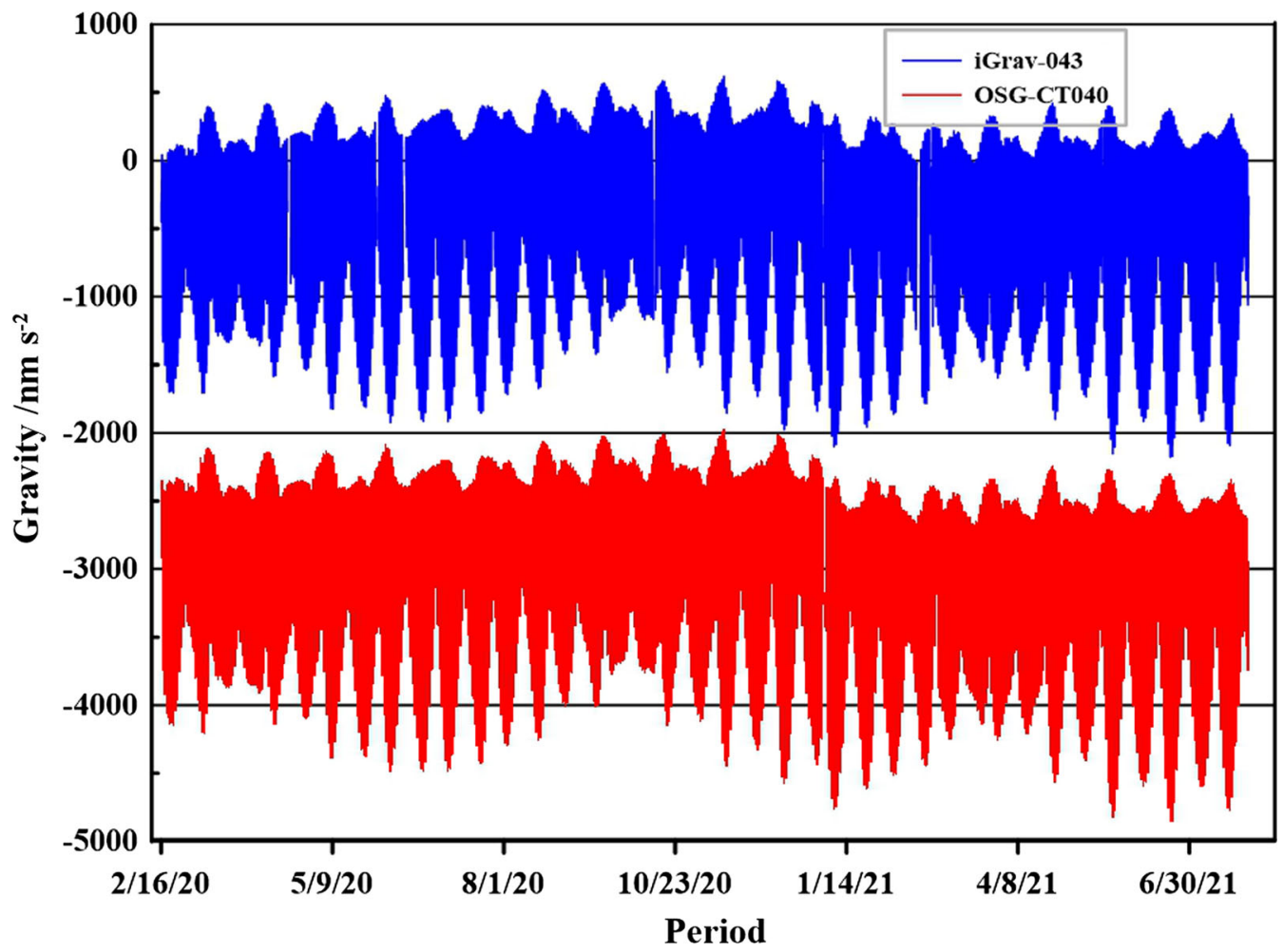

Figure 3

Gravity data from the OSG-CT040 (red) and iGrav-043 (blue) from 16.02.2020 to 01.08.2021 in the Walferdange Underground Laboratory for Geodynamics

two most widely used and efficient methods are either a calibration transfer between two relative gravimeters (Francis \& Hendrickx, 2001) or a linear regression analysis between the observations of the relative gravimeter under calibration and those of an absolute gravimeter (Francis et al., 1998). In our case, the OSG-CT040 was calibrated with a FG5 absolute gravimeter with a precision of $0.1 \%$ (Lampitelli \& Francis, 2009). We could then transfer its calibration factor to the iGrav-043.

The procedure is very simple. Using one month of simultaneous data, a first guess calibration factor is estimated by applying a linear fit between the iGrav043 and the calibrated OSG-CT040 measurements. In the fitting procedure, a third-degree polynomial is included to model the instrumental drifts of both gravimeters. The applied formula thus reads.

$$
\mathrm{g}_{O S G}=\alpha \cdot \mathrm{g}_{i G r a v}+a \cdot t^{3}+b \cdot t^{2}+c,
$$

where $g_{i G r a v}$ is the output gravity voltage of the iGrav-043 and gosG is the calibrated gravity value in $\mathrm{nm} \mathrm{s}{ }^{-2}$ from the OSG-CT040. The slope $\alpha$ represents the scale or $\mathrm{CF}$ in $\mathrm{nm} \mathrm{s}{ }^{-2} /$ Volt and the terms $\mathrm{a}, \mathrm{b}$ and $\mathrm{c}$ are the coefficients of the third-degree polynomials to model the instrumental drifts. We obtained a first guess CF of $-925.08 \pm 0.28 \mathrm{~nm} \mathrm{~s}^{-2} /$ Volt. It provides an excellent first estimate with a precision of $\pm 0.03 \%$. However, its precision is limited due to the complexity of the instrumental drifts (Meurers, 2012), especially during the first months after the installation. The initial $\mathrm{CF}$ is then improved by comparing the results of tidal analyses of at least 6-month of continuous observations. Such a duration is needed for a better frequency separation between the different tidal waves (Table 1). An admittance factor between the gravity and the atmospheric pressure data is estimated conjointly with the tidal parameters. The values are $-3.20 \pm 0.01 \mathrm{~nm} \mathrm{~s}^{-2}$ and $-3.18+/ 0.01 \mathrm{~nm} \mathrm{~s}^{-2}$ for the OSG-CT040 and 
Table 1

Tidal Parameters estimated using 196 days (15.02.2020 to 01.09.2020) of observations of the OSG-CT40 and iGrav-043 in the Walferdange Underground Laboratory for Geodynamics (latitude $=49.6647^{\circ}$, longitude $=6.1528^{\circ}$, altitude $=295 \mathrm{~m}$ )

\begin{tabular}{|c|c|c|c|c|c|c|c|c|c|c|c|}
\hline \multirow[t]{2}{*}{ Wave } & \multicolumn{3}{|l|}{ Freq } & \multicolumn{4}{|c|}{ OSG-CT040 } & \multicolumn{4}{|c|}{ IGrav-043 } \\
\hline & $\begin{array}{l}\text { Start/ } \\
\text { cpd* }^{*}\end{array}$ & End/cpd & $\begin{array}{l}\text { Amplitude/ } \\
\mathrm{nm} \mathrm{s}^{-2}\end{array}$ & $\begin{array}{l}\text { Delta } \\
\text { factor }\end{array}$ & Std Dev & $\begin{array}{l}\text { Phase lead/ } \\
\text { degree }\end{array}$ & $\begin{array}{l}\text { Std dev/ } \\
\text { degree }\end{array}$ & $\begin{array}{l}\text { Delta } \\
\text { factor }\end{array}$ & Std Dev & $\begin{array}{l}\text { Phaselead/ } \\
\text { degree }\end{array}$ & $\begin{array}{l}\text { Std dev/ } \\
\text { degree }\end{array}$ \\
\hline $\mathrm{Q}_{1}$ & 0.721500 & 0.906315 & 67.489 & 1.14978 & 0.00055 & -0.3673 & 0.0318 & 1.14966 & 0.00058 & -0.3727 & 0.0334 \\
\hline $\mathrm{O}_{1}$ & 0.921941 & 0.940487 & 352.092 & 1.14847 & 0.00011 & 0.0613 & 0.0062 & 1.14880 & 0.00011 & 0.0569 & 0.0065 \\
\hline $\mathrm{M}_{1}$ & 0.958085 & 0.974188 & 27.714 & 1.14942 & 0.00095 & 0.3639 & 0.0549 & 1.14904 & 0.00101 & 0.3730 & 0.0578 \\
\hline $\mathrm{P}_{1}$ & 0.989049 & 0.998028 & 163.901 & 1.14899 & 0.00024 & 0.0698 & 0.0143 & 1.14893 & 0.00026 & 0.0727 & 0.0151 \\
\hline $\mathrm{K}_{1}$ & 0.999853 & 1.011099 & 490.543 & 1.13771 & 0.00008 & 0.2225 & 0.0044 & 1.13797 & 0.00008 & 0.2167 & 0.0047 \\
\hline $\mathrm{J}_{1}$ & 1.013689 & 1.044800 & 27.876 & 1.15617 & 0.00135 & 0.1641 & 0.0774 & 1.15595 & 0.00142 & 0.2247 & 0.0815 \\
\hline $\mathrm{OO}_{1}$ & 1.064841 & 1.216397 & 15.250 & 1.15626 & 0.00205 & -0.0109 & 0.1171 & 1.15731 & 0.00215 & -0.0250 & 0.1233 \\
\hline $2 \mathrm{~N}_{2}$ & 1.719381 & 1.872142 & 11.042 & 1.14707 & 0.00132 & 3.2656 & 0.0755 & 1.14807 & 0.00136 & 3.1896 & 0.0779 \\
\hline $\mathrm{N}_{2}$ & 1.888387 & 1.906462 & 70.341 & 1.16693 & 0.00027 & 3.1155 & 0.0153 & 1.16718 & 0.00028 & 3.1165 & 0.0158 \\
\hline $\mathrm{M}_{2}$ & 1.923766 & 1.942754 & 373.825 & 1.18736 & 0.00005 & 2.3452 & 0.0030 & 1.18773 & 0.00005 & 2.3402 & 0.0031 \\
\hline $\mathrm{L}_{2}$ & 1.958233 & 1.976926 & 10.231 & 1.14971 & 0.00183 & 1.9926 & 0.1048 & 1.15126 & 0.00189 & 2.0084 & 0.1081 \\
\hline $\mathrm{S}_{2}$ & 1.991787 & 2.002885 & 174.551 & 1.19164 & 0.00012 & 0.7066 & 0.0068 & 1.19183 & 0.00012 & 0.7192 & 0.0071 \\
\hline $\mathrm{K}_{2}$ & 2.003032 & 2.182843 & 47.584 & 1.19530 & 0.00041 & 0.8781 & 0.0235 & 1.19538 & 0.00042 & 0.8766 & 0.0243 \\
\hline $\mathrm{M}_{3}$ & 2.753244 & 3.081254 & 4.259 & 1.06178 & 0.00207 & 0.2678 & 0.1188 & 1.06315 & 0.00188 & 0.3068 & 0.1079 \\
\hline
\end{tabular}

The OSG-CT040 calibration factor was obtained by comparison with an absolute gravimeter FG5. In this analysis of the iGrav-043, we used a first-guess calibration factor (see text). Positive values of the "Phase Lead" mean that the gravity observations are in advance with respect to the tidal potential

*cpd means cycle per day

the iGrav-043, respectively. The values match within the error bars. In other words, the sensitivity of both gravimeters to the atmospheric pressure is identical.

The longer the time series are, the more tidal constituents can be estimated with a better precision. The advantage of this approach is that the data are low-passed filtered prior tidal analysis eliminating drifts and high frequency noise (like micro-seismic noise). We then take the ratio between the amplitude of the largest tidal constituents to obtain the final CF.
From the uncertainties estimated in ETERNA (Wenzel, 1996), we then estimate the uncertainty on the new CF (Table 2).

The ratios of the amplitudes of the delta factor of each constituent represent the ratios of the $\mathrm{CF}$ at specific frequencies between the two gravimeters. To increase the precision, we calculate the mean value for the three tidal constituents with the largest amplitude $\left(\mathrm{K}_{1}, \mathrm{M}_{2}\right.$ and $\left.\mathrm{O}_{1}\right)$. Their contributions in the final value are weighted according to their

Table 2

Comparison between the amplitudes of the main tidal constituents estimated with 196 days (from (15.02.2020 to 01.09.2020) of simultaneous data of the OSG-CT040 and iGrav-043

\begin{tabular}{lllr}
\hline Wave & OSG-CT040 & iGrav-043 & $\begin{array}{l}\text { iGrav-043 } \\
\text { /OSG-CT040 } \\
\text { Ratio }\end{array}$ \\
\hline $\mathrm{O}_{1}$ & Delta Factor & Delta Factor & $0.99971 \pm 0.00014$ \\
$\mathrm{~K}_{1}$ & $1.14847 \pm 0.00011$ & $1.14880 \pm 0.00011$ & $0.99977 \pm 0.00010$ \\
$\mathrm{M}_{2}$ & $1.13771 \pm 0.00008$ & $1.13797 \pm 0.00008$ & $0.99969 \pm 0.00006$ \\
\hline
\end{tabular}

We used a first estimate of the calibration factor of $-925.08 \pm 0.28 \mathrm{~nm} \mathrm{~s}^{-2} /$ Volt (see text) 
uncertainty (Table 3). The uncertainty of the weighted average is calculated by averaging the delta factors uncertainties. Indeed, we cannot consider the three estimates as independent. The final CF value is $-924.81 \pm 0.07 \mathrm{~nm} \mathrm{~s}^{-2} /$ Volt, i.e. $0.27 \mathrm{~nm} \mathrm{~s}^{-2} /$ Volt less than our first guess. The calculated uncertainty represents the precision of the calibration factor

Table 3

The final value of the calibration factor of the iGrav-043 including its uncertainty assessment

Weighted averaged ratio of Calibration factors the amplitude of the three main tidal waves

\begin{tabular}{|c|c|}
\hline & $\begin{array}{l}\text { First guess } \mathrm{nm} \mathrm{s}^{-2} / \text { Final estimate } \\
\quad \text { Volt } \\
\mathrm{nm} \mathrm{s} \mathrm{s}^{-2} / \text { Volt }\end{array}$ \\
\hline $0.99971 \pm 0.00008$ & $-925.08 \pm 0.28-924.80 \pm 0.75$ \\
\hline
\end{tabular}

transfer but one also needs to consider the uncertainty of the calibration factor of the OSG-CT040. It was calibrated with an absolute gravimeter FG5 with a precision of $\pm 0.75 \mathrm{~nm} \mathrm{~s}^{-2} /$ Volt. This is thus the final precision on the calibration factor of the iGrav043. This "absolute" precision is 10 times larger than the precision of the calibration transfer using tidal analyses. In absolute terms, the first guess calibration with 196 days of data was good enough. By using the comparison between tidal constituents, we obtain a match 10 times better between the observations of both gravimeters.

\subsection{High Frequency Noise}

We selected 5 days of quiet data from which all known geophysical corrections were applied. Then, a 7th degree-polynomial was adjusted to remove

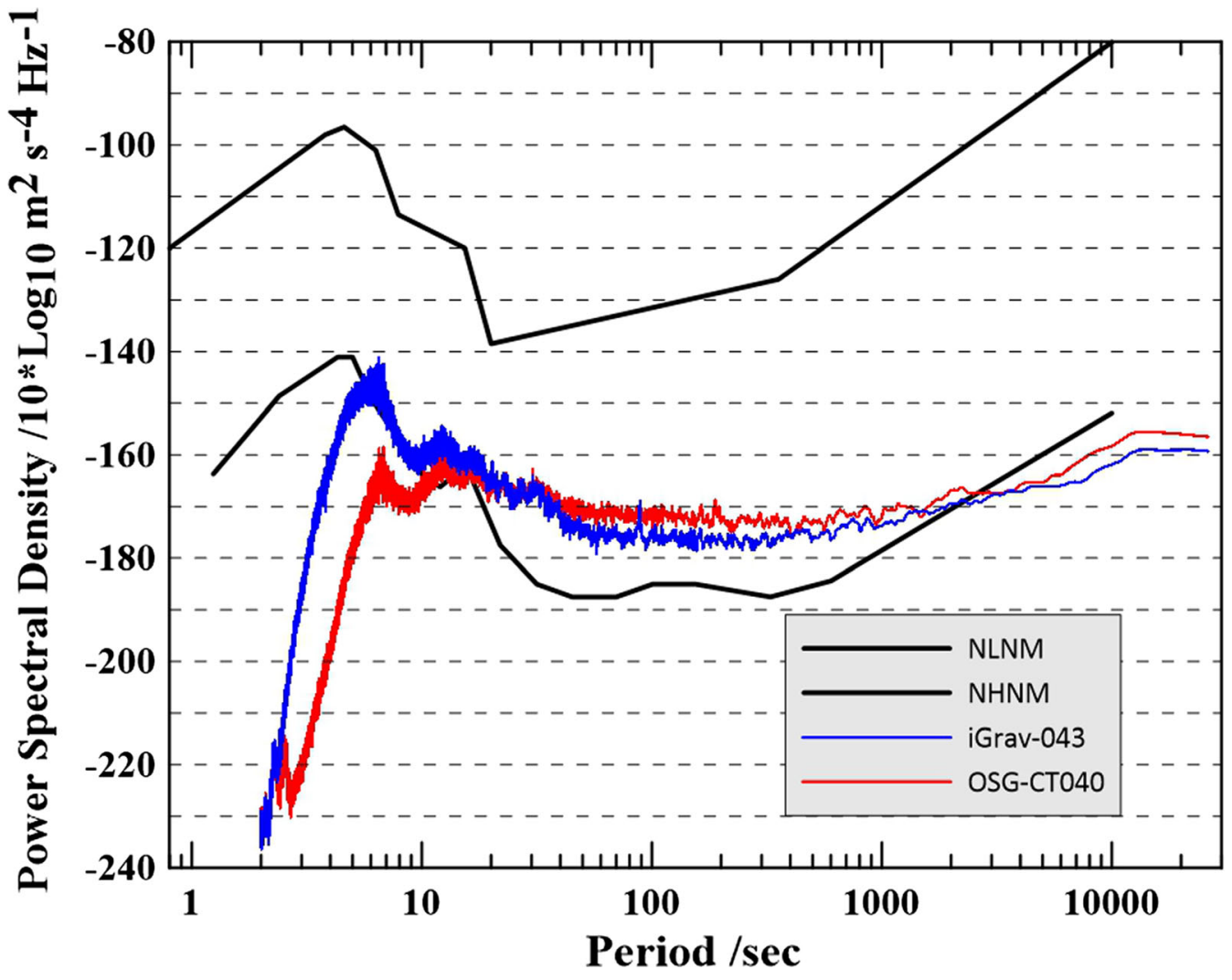

Figure 4

Power Spectral Density (PSD) of the residuals representing the instrumental noise of OSG-CT040 (red) and iGrav-043 (blue) in WULG as compared to the USGS low noise model (NLNM) and USGS high noise model (NHNM) of Peterson (1993) 
instrumental drifts and any remaining environmental noises. All the Power Spectral Densities (PSD) are averaged to produce the PSD of the residuals. The results represent the instrumental noises that can be compared with the standard model noise model of Peterson (1993). Figure 4 shows that the noise level at the Walferdange laboratory is in the low standards. It is also apparent that the iGrav-043 performs slightly better between 20 and $5000 \mathrm{~s}$. At periods shorter than $20 \mathrm{~s}$, the difference originates from the use of a different analog low-passed filter.

The characteristics of the tide low-pass filter of the OSG-CTO40 are given in the GWR Manual (GEP-3 Operator's Manual, 2000): “The lowpass filter consists of two cascaded three pole filters with $3 \mathrm{~dB}$ cutoff frequency, $\mathrm{f}_{\mathrm{c}}$, at $1.95 \times 10^{-2} \mathrm{~Hz}\left(\mathrm{~T}_{\mathrm{c}}=\right.$ $50 \mathrm{~s})$. The low-pass has unity gain at low frequencies and a high frequency attenuation rate of $36 \mathrm{~dB}$ per octave." The iGRAV-043 low-pass filter is a 4 pole Butterworth filter with the following characteristics: group delay $1.542 \mathrm{~s}$, attenuation $100 \mathrm{~dB}$ at $5 \mathrm{~Hz}$; gain of $-0.00042 \mathrm{~dB}$ at $10 \mathrm{mHz}$, gain of $-0.25 \mathrm{~dB}$ at $100 \mathrm{mHz}$ and gain of $-45.42 \mathrm{~dB}$ at $1 \mathrm{~Hz}$ (Warburton, personal communication).

Above $5000 \mathrm{~s}$, the OSG-CT40 looks slightly better as confirmed by the tidal analyses (see Sect. 3.1).

\subsection{Instrumental Drift}

The difference between the OSC-CT040 and iGrav-043 raw data using the final calibration factor represents the difference between the instrumental drift of both gravimeters. After 20 years of continuous operation, the OSCG-CT040 is almost drift free, with an estimate for the instrumental drift being

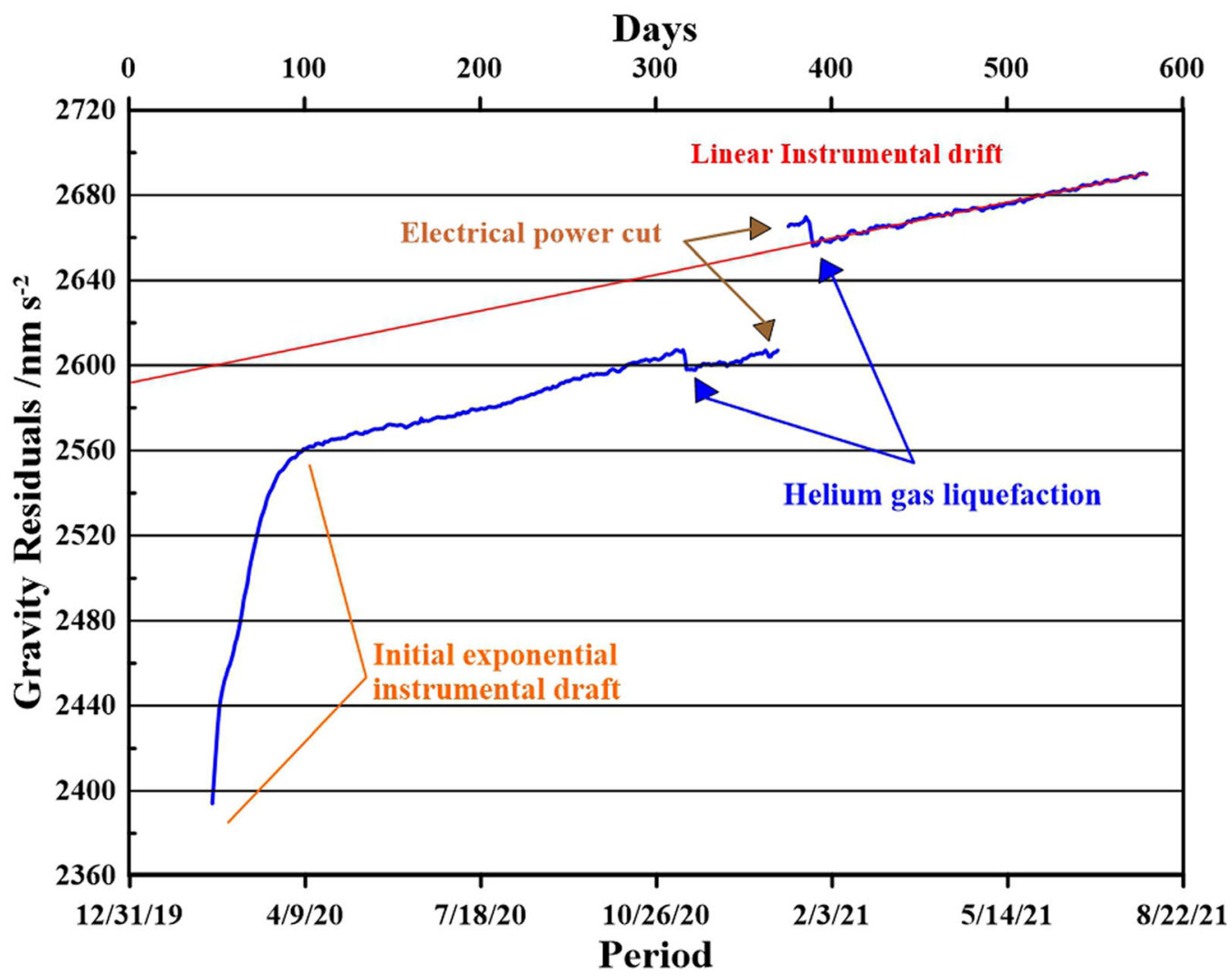

Figure 5

Difference between the iGrav-043 and OSG-CT40 measurements corresponding to the instrumental drift of the iGrav-043 as the OSG-CT040 has a drift less than $10 \mathrm{~nm} \mathrm{~s}^{-2}$ per year 
$0.0 \pm 10 \mathrm{~nm} \mathrm{~s}^{-2}$ per year. Figure 5 shows the difference between the iGrav-043 and OSG-CT040 observations which corresponds to the instrumental drift of the iGrav-043. Immediately after the installation, the initial drift shows a fast exponential increase of $160 \mathrm{~nm} \mathrm{~s}^{-2}$ over 1.5 month. Then the instrumental drift becomes almost perfectly linear with a constant rate of $66 \mathrm{~nm} \mathrm{~s}^{-2} \pm 10 \mathrm{~nm} / \mathrm{s}^{-2}$ per year. This behavior is common to all SGs.

We also observe two steps induced by the Helium gas liquefaction. The offsets are always negative with a value around $10 \mathrm{~nm} \mathrm{~s}^{-2}$. Another step and data interruption are due to an electrical power cut. It did not affect the behavior of the instrumental of the iGrav-043 as discussed in details in the following section.

\subsection{Drift Behavior After Electrical Shortage}

From the 3 to 6 of January 2021, the power supply cable of the WULG was unexpectedly cut. It was followed by several interruptions of the electrical alimentation of the gravimeters before the situation could be stabilized. Once the power is off, the feedback voltage to maintain the levitating sphere is not active anymore and is free to move. As long as there is still liquid Helium in the dewar, the sphere will keep levitating. This rare event gave us the opportunity to observe how different types of SG react and recover following electrical cut offs. In Sect. 3.3, we already saw that the long-term linear behavior of the drift was not affected (see Fig. 5). This is the best-case scenario, although it produces an offset in the gravity data. Its amplitude could be determined at the cost of additional absolute gravity measurements.

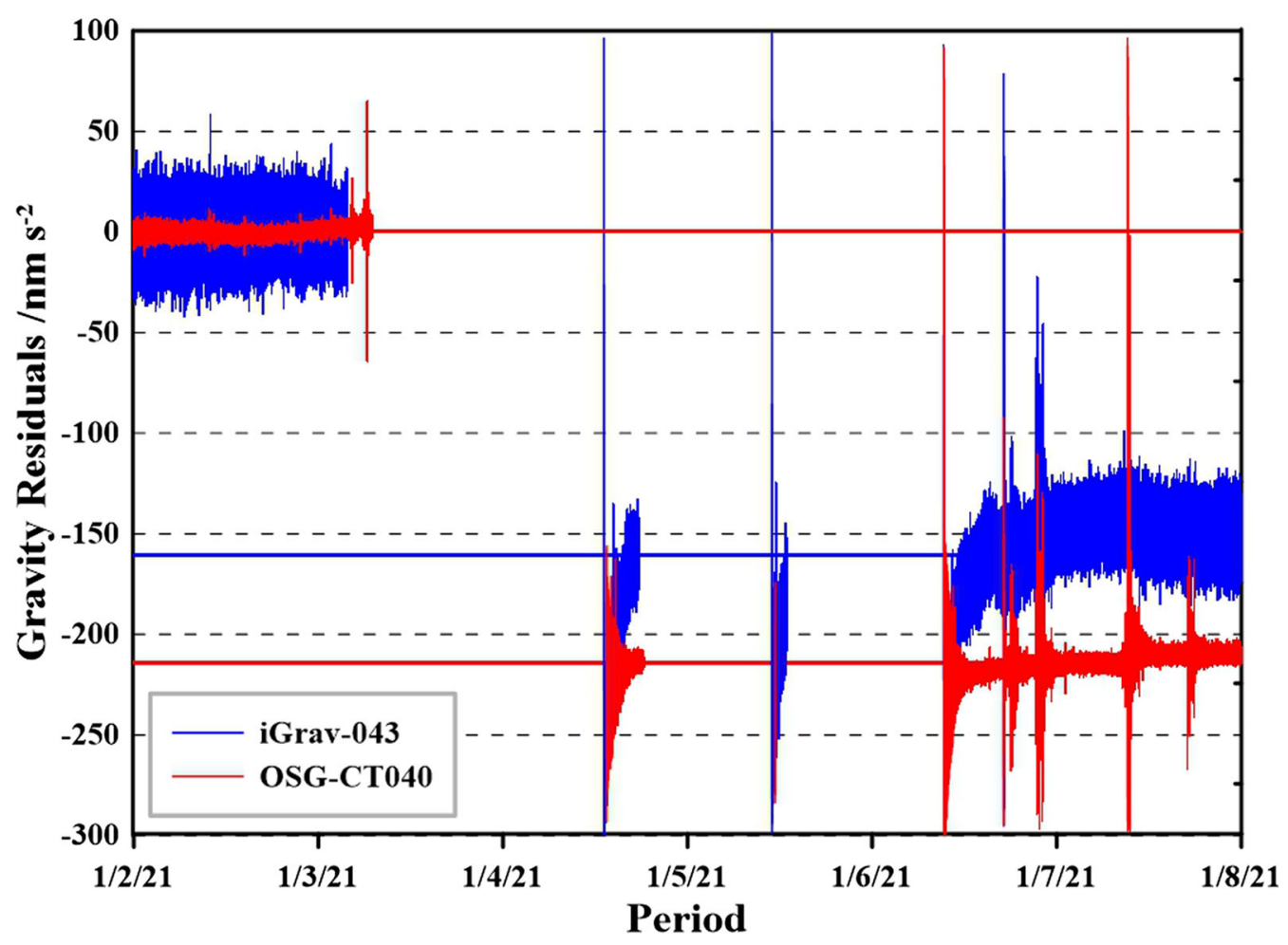

Figure 6

Gravity residuals of the OSG-CT040 (red) and iGrav-043 (blue) during electrical cutoffs. Data sampling of $1 \mathrm{~s}$ 


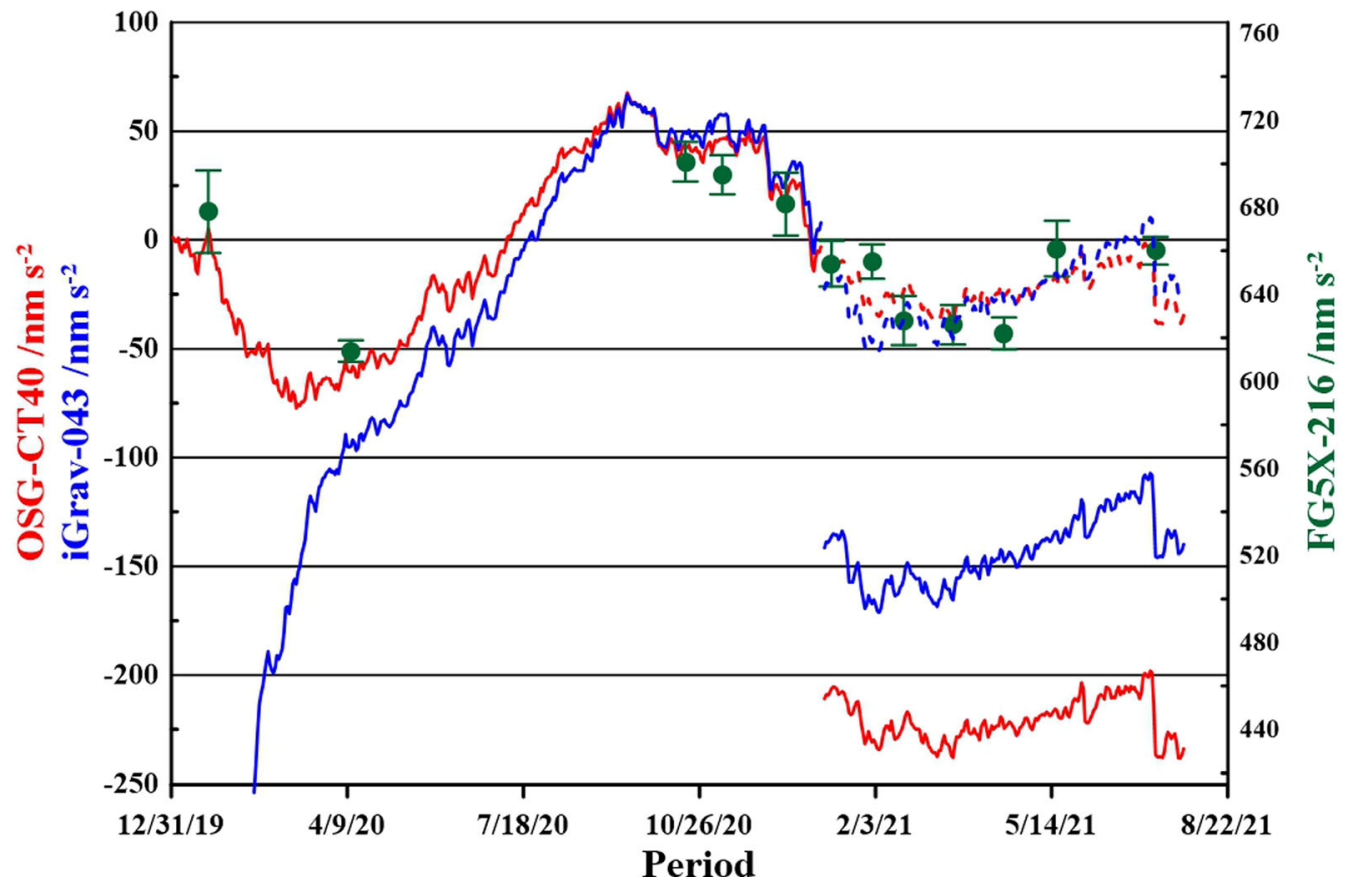

Figure 7

Comparison between the OSG-CT040 (red), iGrav-043 (blue) and FG5X-216 (green) data corrected to tides and atmospheric pressure effect. An offset of 9,809,640,000 $\mathrm{nm} \mathrm{s}^{-2}$ has been removed from the FG5X-216 data. The dashed lines stand for the residuals of OSG-CT040 and iGrav-043 after removing their offsets

The electric power was cut off one time during the incident and then successively switched off and on two times to fix the deficient electrical cable. The gravity residuals, before and after these events, are shown in Fig. 6 for both SGs. Both experienced a negative offset of $-214 \mathrm{~nm} \mathrm{~s}^{-2}$ and $-161 \mathrm{~nm} \mathrm{~s}^{-2}$ for the OSC-CT040 and iGrav-036, respectively. Fortunately, there is an offset only after the first cutoff. No offsets are detectable after the two provoked electrical power interruptions for the repair of the electrical line. There is no explanation as no specific or preventive actions were taken before switching the power off manually. Once the electric power is switched back on, the free mode of the levitated sphere of the OSG-CT040 is excited and disappears after a few hours. Interestingly, there is no apparent excitation of the free mode on the iGrav043. However, the iGrav-043 curve shows a relaxation lasting for few hours. This relaxation is well correlated with the temperature control voltage. It seems that the relaxation vanishes once the temperature of the sensor reaches its normal operational value. For the OSG-CT040, we could not look closely at the different parameters (tilts, temperature, etc.). The PC of the acquisition system broke due to the power cut.

\subsection{Validation with Absolute Gravity Data}

Absolute gravity measurements were carried out once a month except during the maintenance of the absolute gravimeter between April and October 2020 and. In, we compare the data from both SGs corrected for tides and atmospheric pressure effects with the observations of the absolute gravimeter FG5X-216. The main visible signal is the centrifugal acceleration due to the polar motion, whose correction was not applied.

The OSC-CT040 has no detectable drift over the considered period. The instrumental drift of the iGrav-043 is clearly visible and confirmed by the absolute gravity data. We can also see the offsets caused by an electrical power cut with an amplitude of about 150 and $200 \mathrm{~nm} / \mathrm{s}^{2}$ for the iGrav-043 and 
OSG-CT040, respectively. In order to clearly see the residuals of iGrav-043 and OSG-CT040 w.r.t. the absolute gravity measurements of the FG5X-216, their offsets have been removed as shown in Fig. 7 (dashed lines).

\section{Conclusions}

In this paper, the calibration factor of the latest version of GWR superconducting gravimeters, represented by the iGrav-043 instrument, was estimated taking advantage of the data of an older instrument, the OSG-CT040. The latter SG was calibrated with a FG5 absolute gravimeter with a precision of $0.1 \%$; this was then transferred to calibrate the iGrav-043 superconducting gravimeter providing a factor of $-924.80+-0.75 \mathrm{~nm} \mathrm{~s}^{-2} /$ Volt. It was estimated by comparing the amplitude of the main tidal constituents estimated with 6 months of data. A longer duration would not result in a better calibration factor as the precision of the transfer is 10 times better that the calibration of "reference" SG calibrated with an absolute gravimeter.

The power spectral density of the iGrav-043 residuals shows a noise level at the Walferdange station in the low standards performing slightly better than the OSG-CT040 between periods of 20 and $5000 \mathrm{~s}$. Beyond $5000 \mathrm{~s}$, the OSG-CT40 looks slightly better as confirmed by the tidal analyses. The instrumental drift of the iGrav-43 shows the expected behavior: for the first and a half month a fast exponential decrease in the drift of $171 \mathrm{~nm} \mathrm{~s}^{-2}$ followed by a linear drift with a rate of $66 \mathrm{~nm} \mathrm{~s}^{-2-}$ $\pm 10 \mathrm{~nm} \mathrm{~s}^{-2}$ per year. It has been also found, after electrical shortages of short period over 3 days, that the long-term linear behaviors of the instrumental drift of both SGs are not affected.

\section{Acknowledgements}

The Funding of the German Research foundation (under Grant INST217/887-1) for purchasing the iGrav-043 is deeply acknowledged.
Author Contributions Conceptualization: $[\mathrm{BE}]$ and $[\mathrm{OF}]$; Methodology: $[\mathrm{BE}]$ and $[\mathrm{OF}]$; Formal analysis and investigation: $[\mathrm{OF}]$ and $[\mathrm{BE}]$ Writing-original draft preparation: $[\mathrm{BE}]$; Writing-review and editing: $[\mathrm{BE}],[\mathrm{OF}]$ and $[\mathrm{JK}]$; Funding acquisition: [JK]; Supervision, [JK] and $[\mathrm{OF}]$. All authors have read and agreed to the published version of the manuscript.

\section{Funding}

Open Access funding enabled and organized by Projekt DEAL.

Open Access This article is licensed under a Creative Commons Attribution 4.0 International License, which permits use, sharing, adaptation, distribution and reproduction in any medium or format, as long as you give appropriate credit to the original author(s) and the source, provide a link to the Creative Commons licence, and indicate if changes were made. The images or other third party material in this article are included in the article's Creative Commons licence, unless indicated otherwise in a credit line to the material. If material is not included in the article's Creative Commons licence and your intended use is not permitted by statutory regulation or exceeds the permitted use, you will need to obtain permission directly from the copyright holder. To view a copy of this licence, visit http:// creativecommons.org/licenses/by/4.0/.

Publisher's Note Springer Nature remains neutral with regard to jurisdictional claims in published maps and institutional affiliations.

\section{REFERENCES}

Achilli, V., Baldi, P., Casula, G., Errani, M., Focardi, S., Guerzoni, M., et al. (1995). A calibration system for superconducting gravimeters. Bulletin Géodésique, 69, 73-80.

Almavict, M., Hinderer, J., Francis, O., \& Mäkinen, J. (1998). Comparisons between absolute (AG) and superconducting (SG) gravimeters, Geodesy on the Move. International Assocation of Geodesy Symposium, 119, 24-29.

Boy, J.-P., Llubes, M., Hinderer, J., \& Florsch, N. (2003). A comparison of tidal ocean loading models using superconducting gravimeter data. Journal of Geophysical Research, 108(B4), 2193. https://doi.org/10.1029/2002JB002050 
Falk, R., Harnisch, M., Harnisch, G., Nowak, I., Richter, B., \& Wolf, P. (2001). Calibration of the supercond-ucting gravimeters SG103, C023, CD029 and CD030. Journal of Geodetic Society of Japan, 47(1), 22-27.

Fores, B., Champollion, C., Le Moigne, N., Bayer, R., \& Chéry, J. (2017). Assessing the precision of the iGrav superconducting gravimeter for hydrological models and karstic hydrological process identification. Geophysical Journal International, 208, 269-280. https://doi.org/10.1093/gji/ggw396

Fores, B., Klein, G., Le Moigne, N., \& Francis, O. (2019). Longterm stability of tilt-controlled gPhoneX gravimeters. Journal of Geophysical Research. Solid Earth, 124(11), 12264-12276. https://doi.org/10.1029/2019JB018276

Francis, O. (1997). Calibration of the C021 superconducting gravimeter in Membach (Belgium) using 47 days of absolute gravity measurements. Interantional Assocation Geodesy Symposia Gravity Geoid and Marine Geodesy, 117, 212-219.

Francis, O., \& Hendrickx, M. (2001). Calibration of the LaCosteRomberg 906 by comparison with the Superconducting Gravimeter C021 in Membach (Belgium). Journal of Geodetic Society of Japan, 47(1), 16-21.

Francis, O., \& van Dam, T. M. (2002). Evaluation of the precision of using absolute gravimeters to calibrate superconducting gravimeters. Metrologia, 39, 485-488.

Francis, O., \& van Dam, T. M. (2003). (2003) Processing of the Absolute data of the ICAG01. Cahiers Du Centre Européen De Géodynamique Et De Séismologie, 22, 45-48.

Francis, O., et al. (2013). The European comparison of absolute gravimeters 2011 (ECAG-2011) in Walferdange. Luxembourg: Results and recommendations. Metrologia, 50, 275-268. https:// doi.org/10.1088/0026-1394/50/3/257

Francis, O., Niebauer, T. M., Sasagawa, G., Klopping, F., \& Gschwind, J. (1998). Calibration of a superconducting gravimeter by comparison with an absolute gravimeter FG5 in Boulder. Geophysical Research Letters, 25(7), 1075-1078.

GEP-3 Operator's Manual, GWR Instruments, Inc., 128 pages, 2000.

Goto, H., Ikeda, H., Sugihara, M., \& Ishido, T. (2020). Laboratory test of a superconducting gravimeter without a cryogenic refrigerator: Implications for noise surveys in geothermal fields. Exploration Geophysics. https://doi.org/10.1080/08123985.2020. 1722027

Güntner, A., Reich, M., Mikolaj, M., Creutzfeldt, B., Schroeder, S., \& Wziontek, H. (2017). Landscape-scale water balance monitoring with an iGrav superconducting gravimeter in a field enclosure. Hydrology and Earth System Sciences, 21, 3167-3182. https://doi.org/10.5194/hess-21-3167-2017

Hinderer, J., Calvo, M., Abdelfettah, Y., Hector, B., Riccardi, U., Ferhat, G., \& Bernard, J.-D. (2015). Monitoring of a geothermal reservoir by hybrid gravimetry; feasibility study applied to the Soultz-sous-Forêts and Rittershoffen sites in the Rhine graben. Geothermal Energy. https://doi.org/10.1186/s40517-015-0035-3

Hinderer, J., Crossley, D., \& Warburton, R. (2007). Gravimetric methods-superconducting gravity meters. Treatise Geophysics, $3,65-122$.

Hinderer, J., Florsch, N., Mäkinen, J., Legros, H., \& Faller, J. E. (1991). On the calibration of a superconducting gravimeter using absolute gravity measurements. Geophysical Journal International, 106, 491-497.

iGrav User's Guide (2019) iGravs-042 thru 047. GWR Instruments iGrav® User's Guide. Revision 4.01. 13 Dec 2019.
Imanishi, Y., Higashi, T., \& Fukuda, Y. (2002). (2002) Calibration of the superconducting gravimeter T011 by parallel observation with the absolute gravimeter FG5 \#210-a Bayesian approach. Geophysical Journal International, 151(3), 867-878. https://doi. org/10.1046/j.1365-246X.2002.01806.x

Lampitelli, C., \& Francis, O. (2009). Hydrological effects on gravity and correlations between gravitational variations and level of the Alzette River at the station of Walferdange. Luxembourg. Journal of Geodynamics. https://doi.org/10.1016/j.jog. 2009.08.003

Melchior, P., Ducarme, B., \& Francis, O. (1996). The response of the Earth to tidal body forces described by second-and thirddegree spherical harmonics as derived from a 12 year series of measurements with the superconducting gravimeter GWR/T3 in Brussels. Physics of the Earth \& Planetary Interiors, 93(3), 223-238.

Merlet, S., Gillot, P., Cheng, B., et al. (2021). (2021) Calibration of a superconducting gravimeter with an absolute atom gravimeter. Journal of Geodesy, 95, 62. https://doi.org/10.1007/s00190-02101516-6

Meurers, B. (2012). Superconducting Gravimeter Calibration by CoLocated Gravity Observations: Results from GWR C025. International Journal of Geophysics. https://doi.org/10.1155/2012/ 954271

Okubo, S., Yoshida, S., Sato, T., Tamura, Y., \& Imanishi, Y. (1997). Verifying the precision of a new generation absolute gravimeter FG5 - Comparison with superconducting gravimeters and detection of oceanic loading tide. Geophysical Research Letters, 24(4), 489-492. https://doi.org/10.1029/97GL00217

Peterson, J.R. (1993) Observations and modeling of seismic background noise. Doi:https://doi.org/10.3133/ofr93322. USGS Publications Warehouse. http://pubs.er.usgs.gov/publication/ ofr93322.

Prothero, W. A., \& Goodkind, J. M. (1968). A superconducting gravimeter. Review of Scientific Instruments, 39(9), 1257-1262.

Richter B (1990) The long period elastic behavior of the earth. In: McCarthy D and Carter W (eds.) IUGG geophysical monograph No. 59 (9): pp. 21-25.

Richter, B. and Warburton, R. (1989) A new generation of superconducting gravimeters. In: Ducarme. B. and Paquet. E (eds) Proceedings of the 13th International Symposium on Earth Tides. Brussels. 1997. pp. 545-555.

Richter, B., Wilmes, H., \& Nowak, I. (1995). The Frankfurt calibration system for relative gravimeters. Metrologia, 32(3), 217-223.

Rosat, S., Boy, J.-P., Ferhat, G., Hinderer, J., Almavict, M., Gegout, P., \& Luck, B. (2009). Analysis of a 10-year (1997-2007) record of time-varying gravity in Strasbourg using absolute and superconducting gravimeters: New results on the calibration and comparison with GPS height changes and hydrology. Journal of Geodynamics, 48(3-5), 360-365.

Schäfer, F., Jousset, P. H., Güntner, A., Erbas, K., Hinderer, J., et al. (2020). Performance of three iGrav superconducting gravity meters before and after transport to remote monitoring sites. Geophysical Journal International, 223(2), 959-972. https://doi. org/10.1093/gji/ggaa359

Van Camp, M., Simons, S. D. P., \& Francis, O. (2005). Uncertainty of absolute gravity measurements. Journal of Geophysical Research, 110, B05406. https://doi.org/10.1029/2004JB003497

Warburton, R.J. and Brinton, E. (1995) Recent developments inGWRInstruments superconducting gravimeters. Proceedings of 
the 2nd Workshop: Non-tidal Gravity Changes. Intercomparison Between Absolute and Superconducting Gravimeters. Vol. 11. Cahiers du Centre Europeen de Geodynamique et de Seismologie. Luxembourg. pp. 23-56.

Warburton, R.J., Brinton, E., Reineman, R. and Richter, B. (2000) Remote operation of superconducting gravimeters. Proceedings of the Workshop: High Precision Gravity Measurements with Applications to Geodynamics and Second GGP Workshop. Vol. 17. Cahiers du Centre Europeen de Geodynamique et de Seismologie. Luxembourg. pp. 125-136.
Warburton, R.J., Pillai, H., Reineman, R.C. (2010). Initial Results with the New GWR iGrav ${ }^{\text {TM }}$ Superconducting Gravity Meter. International Association of Geodesy (IAG) Symposium Proceedings. IAG Symposium on Terrestrial Gravimetry: Static and Mobile Measurements (TG-SMM2010). 22-25 June 2010. Russia. Saint Petersburg.

Wenzel, H.-G. (1996). The nanogal software: Earth tide data processing package ETERNA 3.30. Bulletin D'informations Marées Terrestres., 124, 9425-9439.

(Received November 8, 2021, revised December 18, 2021, accepted December 20, 2021, Published online January 6, 2022) 